\title{
miR-181b promotes chemoresistance in breast cancer by regulating Bim expression
}

\author{
YABING ZHENG ${ }^{1}$, XIAOAI LV ${ }^{2}$, XIAOJIA WANG ${ }^{1}$, BEI WANG $^{2}$, XIYING SHAO $^{1}$, YUAN HUANG ${ }^{1}$ \\ LEI SHI ${ }^{1}$, ZHANHONG CHEN $^{1}$, JIAN HUANG ${ }^{1}$ and PING HUANG ${ }^{1}$ \\ ${ }^{1}$ Department of Medical Oncology (Breast), Zhejiang Cancer Hospital, Hangzhou, Zhejiang 310022; \\ ${ }^{2}$ Department of Breast Surgery, The First Affiliated Hospital of Zhejiang Chinese Medicine University, \\ Shangcheng, Hangzhou, Zhejiang 310006, P.R. China
}

Received August 9, 2015; Accepted September 14, 2015

DOI: $10.3892 / o r .2015 .4417$

\begin{abstract}
MicroRNAs are emerging as critical regulators of the initiation and progression of multiple types of human cancers, including breast cancer. In the present study, the expression of miR-181b in breast cancer patient serum and breast cancer cell lines was evaluated. It was demonstrated that the miR-181b level was significantly upregulated in patient serum and breast cancer cell lines compared with that in normal controls. The results of in vitro ${ }^{3} \mathrm{H}$ thymidine incorporation and Transwell migration assay indicated that miR-181b overexpression markedly promoted the proliferation and metastasis of breast cancer cells. These data suggest that miR-181b is a tumor promoter in breast cancer. Furthermore, miR-181b expression was found to be upregulated in doxorubicin (DOX)-resistant T-47D cells (T-47D-R) compared with that in the parental T-47D cells, and upregulation of miR-181b expression decreased the anticancer effect of DOX in the T-47D cells. Mechanistic studies demonstrated that the Bim gene, an essential initiator of apoptosis, was inhibited by miR-181b overexpression. We observed that knockdown of miR-181b by its specific inhibitors significantly re-sensitized the T-47D-R cells to the cytotoxicity of DOX. Importantly, we demonstrated that miR-181b inhibitors increased the level of Bim in the T-47D-R cells, resulting in the loss of mitochondrial membrane potential (MMP) and the activation of caspases caused by DOX. In summary, the results of the present study suggest that miR-181b functions as an oncogene during breast cancer development, and the miR$181 \mathrm{~b} / \mathrm{Bim}$ pathway may be a novel target used to overcome the chemoresistance in breast cancer.
\end{abstract}

Correspondence to: Dr Xiaoai Lv, Department of Breast Surgery, The First Affiliated Hospital of Zhejiang Chinese Medicine University, 54 Youdian Road, Shangcheng, Hangzhou, Zhejiang 310006, P.R. China

E-mail: zhejiangxiaoailv@yeah.net

Key words: breast cancer, miR-181b, Bim, DOX resistance, T-47D-R

\section{Introduction}

Breast cancer is one of the most common malignant cancers, and is also the leading cause of cancer-related deaths among women due to the metastatic spread of the cancer to vital organs, such as the lung and liver $(1,2)$. For patients with early breast cancer, surgery is the primary treatment which effectively improves patient long-term survival. However, it is ineffective for individuals with advanced disease, and the systemic chemotherapy is considered as an alternative option when tumor resection is not feasible $(3,4)$. Unfortunately, chemotherapy is mostly ineffective due to the development of chemoresistance in cancer patients (5). Doxorubicin (DOX) is a widely used antitumor antibiotic for the treatment of multiple types of cancers including breast cancer. However, high-dose DOX shows cardiotoxicity as well as killing normal selfreborn cells $(6,7)$. Therefore, efforts have been made to reduce the dose of DOX by reversing chemoresistance $(8,9)$.

MicroRNAs (miRNAs) are a class of small non-coding RNAs, typically 19-25 nucleotides in length. They function as gene regulators by downregulating the expression of specific target genes $(10,11)$. Approximately $50 \%$ of miRNA genes are located in tumor-associated genomic regions, and more than $30 \%$ of all human protein-coding genes may be regulated by miRNAs, including a wide range of genes involved in tumorigenesis $(12,13)$. Therefore, it is well acknowledged that miRNAs are important for cancer development and progression, which can act as either oncogenes or tumor suppressors by regulating their respective target genes $(14,15)$. Studies have indicated that a systematic characterization of miRNAs could enable their identification as biomarkers for the diagnosis of breast cancer, and many miRNAs may be chosen as therapeutic targets for the treatment of breast cancer $(16,17)$. However, the role and the mechanism of miRNAs in tumorigenesis and cancer chemotherapy remain largely unknown.

In the present study, we sought to determine the role of miR-181b in the growth and migration of breast cancer cells. We demonstrated that the expression of miR-181b is upregulated in patients with breast cancer, and is involved in the development and metastasis of breast cancer cells. More importantly, we also present evidence for miR-181b upregulation as a mechanism for DOX resistance, and provide the first 
link between miR-181b and the intrinsic apoptotic pathway activated by DOX in breast cancer.

\section{Materials and methods}

Clinical samples and cell culture. Blood samples were obtained from 30 healthy controls and 30 breast cancer patients at Zhejiang Cancer Hospital (Hangzhou, China). The use of the blood for the present study was approved by the Hospital's Protection of Human Subjects Committee. MCF-10A, T-47D, MCF-7, MDA-MB-231 and MDA-MB-435 cell lines were provided by the Institute of Biochemistry and Cell Biology of the Chinese Academy of Science (Shanghai, China). The breast cancer cell lines (including T-47D, MCF-7, MDA-MB231 and MDA-MB-435) were cultured in Dulbecco's modified Eagle's medium (DMEM) supplemented with $10 \%$ fetal bovine serum (both from Gibco, USA), $100 \mathrm{IU} / \mathrm{ml}$ penicillin and $100 \mu \mathrm{g} / \mathrm{ml}$ streptomycin sulfate. The MCF-10A cell line was cultured in DMEM/F12 media supplemented with 5\% horse serum, $10 \mu \mathrm{g} / \mathrm{ml}$ insulin (all from Gibco), $100 \mathrm{ng} / \mathrm{ml}$ cholera toxin, $20 \mathrm{ng} / \mathrm{ml}$ EGF and $0.5 \mu \mathrm{g} / \mathrm{ml}$ hydrocortisone (all from Sigma-Aldrich, USA) at $37^{\circ} \mathrm{C}$ in a humidified incubator with $5 \% \mathrm{CO}_{2}$. To study the role of miR-181b in chemoresistance, we established a doxorubicin-resistant T-47D cell line (T-47D-R) by stepwise exposure of T-47D cells to increasing concentrations of DOX (Sigma-Aldrich). Briefly, the T-47D cells were initially cultured with $0.1 \mu \mathrm{g} / \mathrm{ml} \mathrm{DOX}$ for 8 weeks, and then the DOX concentration was increased every 4 weeks by $0.02 \mu \mathrm{g} /$ $\mathrm{ml}$ up to a final concentration of $0.3 \mu \mathrm{g} / \mathrm{ml}$. The T-47D-R cells were exposed to DOX over a time period of 12 months. Before the following experiments were performed, the T-47D-R cells were cultured in DOX-free DMEM for 2 weeks.

RNAs and transfection. Human miR-181b mimics, 2'-omethyl modified miR-181b inhibitors, negative control oligonucleotides (NCO) and Bim siRNA were purchased from GenePharma Co. (China). The sequences of RNAs were as follows: miR-181b mimics, 5'-AACAUUCAUUGCUGUCG GUGGGU-3'; miR-181b inhibitors; 5'-ACCCACCGA CAGCAAUGAAUGUU-3'; NCO, 5'-AUCCCAUGGUGGGU UACAUGGUU-3'; and Bim siRNA, 5'-GACCGAGAAGGU AGACAAUUU-3'. The RNAs were transfected into cells with Lipofectamine 2000 (Invitrogen, USA) at the final concentration of $50 \mathrm{nM}$ according to the manufacturer's protocols.

Quantitative real-time PCR ( $q R T-P C R)$. The expression levels of miR-181b and Bim were measured by quantitative RT-PCR (qRT-PCR), using TaqMan MicroRNA assays kit and supplies (Applied Biosystems, USA) according to the manufacturer's instructions. The expression of miR-181b was normalized to U6 snRNA, and the Bim level was normalized to GAPDH. Relative quantities of miR-181b and Bim were calculated using the $2^{-\Delta \Delta \mathrm{Ct}}$ method (18).

Luciferase reporter assay. The Bim 3'-UTR was cloned into the pMIR-REPORT ${ }^{\mathrm{TM}}$ miRNA Expression Reporter Vector (Life Technologies, USA) to generate the wild-type constructs. The mutant plasmid was created by mutating the seed regions of the miR-181b-binding sites (UGAAUGU to UGAUAGU) using the Site-Directed Mutagenesis kit (Takara,
Japan) based on the wild-type constructs. Then, the DualLuciferase Reporter assay (Promega, Madison, WI, USA) was conducted to investigate the interaction between miR-181b and its predicted target gene Bim. Briefly, the T-47D-R cells were co-transfected with the miR-181b mimics or $\mathrm{NCO}$ and Bim 3'UTR or Bim 3'UTR-mutant. Forty-eight hours later, the firefly and Renilla luciferase activities were detected according to the manufacturer's protocol. The firefly luciferase activity was normalized to the Renilla luciferase activity.

Western blot analysis. The whole cells were lysed with RIPA buffer (Cell Signaling Technology, USA) containing $2 \mathrm{mM}$ of phenylmethanesulfonyl fluoride. The samples were then subjected to SDS-PAGE and transferred to nitrocellulose membranes. The membranes were probed with primary antibodies at $4^{\circ} \mathrm{C}$ overnight, and were then incubated with appropriate horseradish peroxidase-conjugated secondary antibodies for $2 \mathrm{~h}$. Blots were developed using an enhanced chemiluminescence detection kit (Pierce, USA). The primary antibodies against Bim, caspase-3, caspase-9, PARP and $\beta$-actin were purchased from Cell Signaling Technology.

Cell viability and proliferation. Breast cancer cells were transfected with miR-181b mimics or miR-181b inhibitors at a final concentration of $50 \mu \mathrm{M}$. Forty-eight hours after transfection, the medium was replaced with fresh medium containing DOX at different concentrations. After culturing for $48 \mathrm{~h}$, the cells were subjected to cell viability assay. DOX concentrations leading to $50 \%$ cell death $\left(\mathrm{IC}_{50}\right)$ were calculated by the viability curve determined by the MTT assay. To determine cell proliferation, the ${ }^{3} \mathrm{H}$ thymidine incorporation assay was used to determine the cell proliferation during the last $6 \mathrm{~h}$ of incubation as previously described (19).

Cell migration in vitro. Breast cancer cells were transfected with miR-181b mimics or inhibitors for $48 \mathrm{~h}$. Before being seeded, the undersurface of the upper chamber of the Transwell was coated with collagen I overnight at $4^{\circ} \mathrm{C}$, and then $1 \times 10^{5}$ cells were seeded in serum-free media on the upper chambers of Transwells with a porous transparent polyethylene terephthalate membrane having a pore size of 8-micron (Corning Costar Corporation, USA), and hydroxyurea (SigmaAldrich) was added to stop cellular proliferation. After $24 \mathrm{~h}$, cells on the undersurface of the upper units were fixed, stained and then counted under a phase-contrast microscope.

Apoptosis and mitochondrialmembrane potential $\left(M M P, \Delta \Psi_{m}\right)$ analysis. Apoptosis was assessed using the Annexin V-FITC apoptosis detection kit (Sigma-Aldrich) according to the manufacturer's protocol. After transfection and DOX treatment, $\mathrm{T}-47 \mathrm{D}-\mathrm{R}$ cells were harvested and rinsed in cold phosphatebuffered saline (PBS), followed by resuspension in 1X Annexin binding buffer at $1 \times 10^{6}$ cells $/ \mathrm{ml}$. Annexin V (5 $\left.\mu \mathrm{l}\right)$ and $0.1 \mu \mathrm{g}$ of propidium iodide (PI) were then added to the cells. Samples were incubated at room temperature for $15 \mathrm{~min}$ in the dark and were analyzed using flow cytometry (Becton-Dickinson, USA). $\Delta \Psi_{\mathrm{m}}$ was detected using 5,5',6,6'-tetrachloro-1,1',3,3'tetraethyl-imidacarbo-cyanine iodide (JC-1; Molecular Probes, USA) as an indicator (20). After treatment, the T-47D-R cells were collected and resuspended with PBS containing JC-1 at 

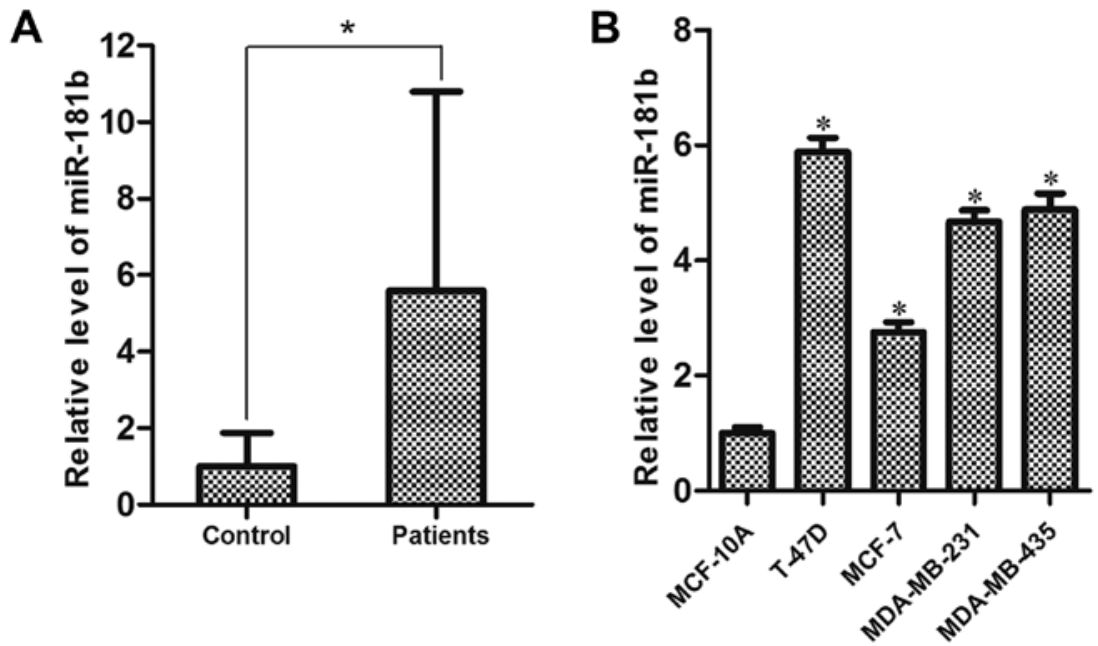

Figure 1. miR-181b is upregulated in breast cancer cell lines and in patient serum. (A) The expression of miR-181b in the serum of breast cancer patients and the healthy controls by RT-qPCR. "p $<0.05$. (B) miR-181b expression in breast cancer cell lines (T-47D, MCF-7, MDA-MB-231 and MDA-MB-435) and normal breast cell line MCF-10A. " p<0.05 vs. MCF-10A.

a final concentration of $5 \mu \mathrm{M}$. Following a 20 -min incubation period at $37^{\circ} \mathrm{C}$ in the dark, MMP was determined by flow cytometric analysis.

Statistical analysis. Data are represented as mean \pm SE of three independent experiments. The Student's t-test was conducted with SPSS 14.0 software to assess the statistical significance between treatments. $\mathrm{p}<0.05$ was considered to indicate a statistically significant result.

\section{Results}

miR-181b is upregulated in breast cancer cell lines and patient serum. The expression of miR-181b was analyzed in the serum of breast cancer patients and the healthy controls using RT-qPCR. miR-181b was significantly upregulated in the cancer patient serum compared with that in the normal controls (Fig. 1A). Furthermore, we found that the expression level of miR-181b was significantly higher in all of the four breast cancer cell lines compared with the level in the normal breast cell line MCF-10A (21) (Fig. 1B). These results suggest that miR-181b may function as a tumor promoter in breast cancer.

miR-181b promotes cell proliferation and migration in breast cancer cells. To study the role of miR-181b in the tumor progression of breast cancer cells, miR-181b mimics or inhibitors were transfected to change the level of miR-181b in the T-47D and MCF-7 cells. Briefly, the miR-181b level was increased $\sim 10.22$-fold after the miR-181b mimics were introduced, and the miR-181b level was decreased $\sim 4.27$-fold after the miR-181b inhibitors were introduced (data not shown). Results of ${ }^{3} \mathrm{H}$ thymidine incorporation assays demonstrated that the proliferation of both T-47D and MCF-7 cells was significantly enhanced in the miR-181b-overexpressing group compared with the control group. In contrast, the proliferation was significantly impaired in the miR-181b-knockdown cells (Fig. 2A). Furthermore, we evaluated the effect of miR-181b on cell migration using a Transwell system. We observed that the overexpression of miR-181b significantly promoted the migration in breast cancer cells, which could be obviously inhibited by knockdown of miR-181b (Fig. 2B). These results suggest that miR-181b may function as a novel oncogene in breast cancer.

miR-181b is associated with the resistance of breast cancer cells to DOX. To investigate whether miR-181b can modulate the sensitivity of breast cancer cells to DOX which is a potent anticancer drug, we stepwisely exposed the T-47D cells to increasing concentrations of DOX to establish a DOX-resistant T-47D cell line (T-47D-R). As shown in Fig. 3A, the expression level of miR-181b in the T-47D-R cells was significantly upregulated compared with that in the parental T-47D cells, suggesting that miR-181b promotes the chemoresistance in breast cancer. To reveal the effects of miR-181b on the efficacy of chemotherapy, T-47D cells were simultaneously treated with miR-181b and DOX. It was found that the miR-181b mimics significantly increased the $\mathrm{IC}_{50}$ of DOX, which was obviously decreased by the transfection of miR-181b inhibitors compared with the controls (Fig. 3B). This indicated that the downregulation of miR-181b sensitized breast cancer cells to DOX resistance. Furthermore, knockdown of miR-181b re-sensitized the T-47D-R (DOX-resistant T-47D) cells to DOX, although the antitumor effect of DOX was not influenced by the transfection of miR-181b mimics (Fig. 3C). Taken together, these results indicated that miR-181b may play an important role in chemoresistance in breast cancer, and that miR-181b silencing reverses the resistance to DOX treatment.

$m i R-181 b$ in T-47D-R cells regulates the expression of Bim. In order to understand the underlying mechanism for the promotion of miR-181b to DOX resistance, we used TargetScan database (http://www.targetscan.org/) and found that Bim was a putative target of miR-181b. Notably, the position $474-480$ of Bim 3'-UTR was observed to be a complementary site $\left(5^{\prime}-\ldots . . . \mathrm{UGAAUGU} . . .-3\right.$ ') for the seed region of miR-181b. Furthermore, we observed that the expression level of Bim was significantly lower in the T-47D-R cells compared with 
A

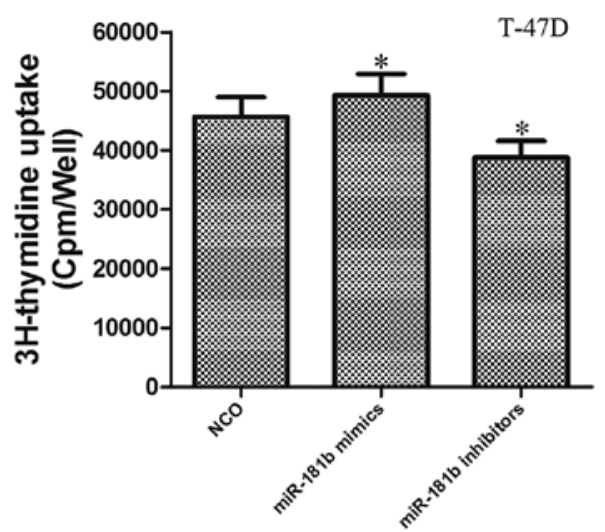

B

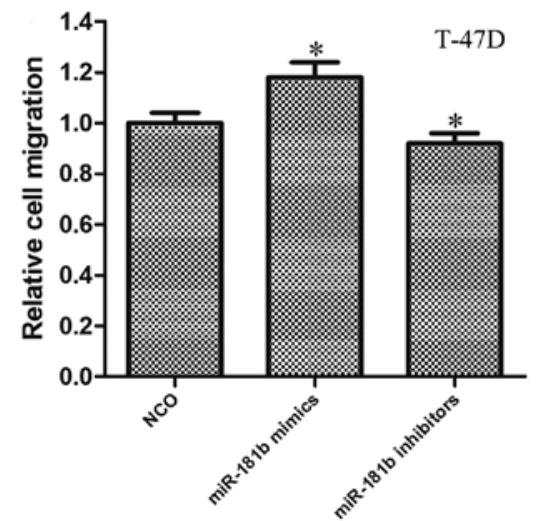

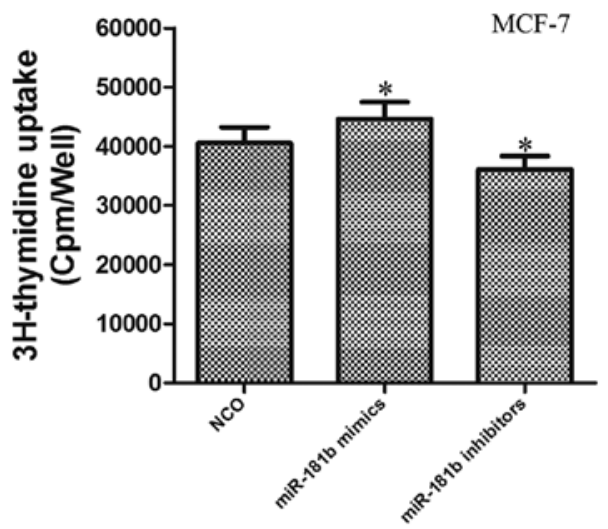

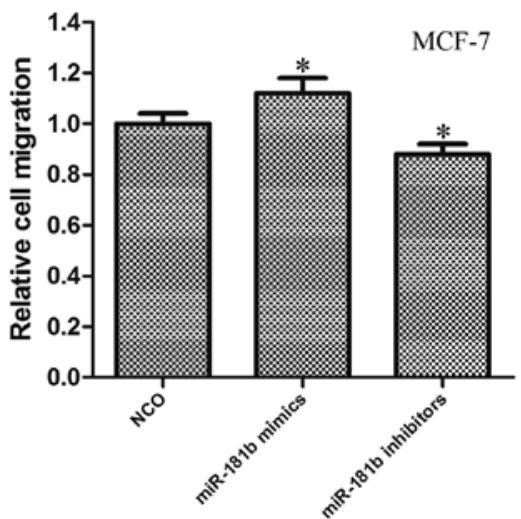

Figure 2. miR-181b promotes cell proliferation and migration in breast cancer cells. (A) After the T-47D and MCF-7 cells were transfected with miR-181b mimics or inhibitors for $48 \mathrm{~h}$, cell proliferation was measured using ${ }^{3} \mathrm{H}$ thymidine incorporation assay. "p<0.05 vs. NCO group. (B) T-47D and MCF-7 cells were transfected with miR-181b mimics or miR-181b inhibitors for $48 \mathrm{~h}$, and the migration potential was analyzed using Transwell assays. Relative cell migration was normalized to the NCO group. ${ }^{*} \mathrm{p}<0.05$ vs. NCO group.

A

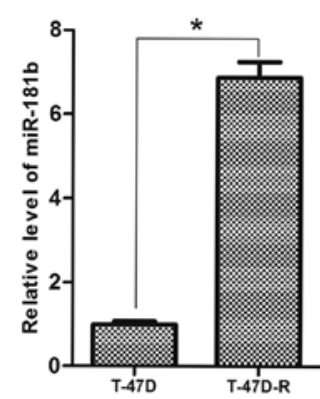

B

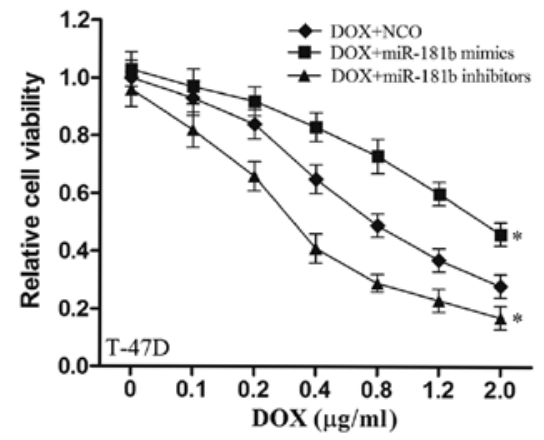

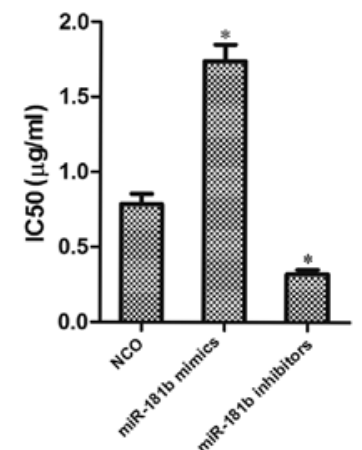
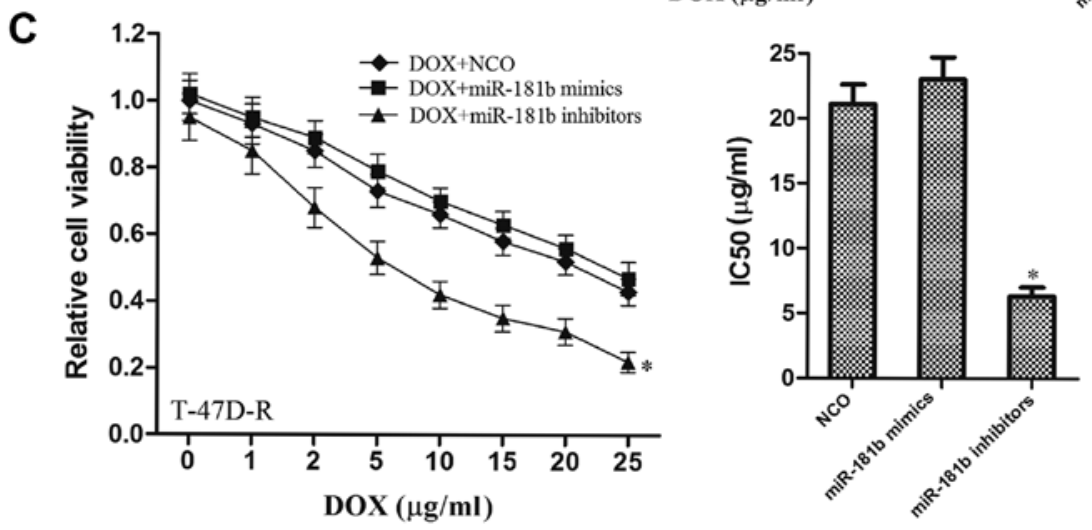

Figure 3. miR-181b is associated with the resistance of breast cancer cells to doxorubicin. (A) The expression of miR-181b in T-47D-R cells and their parental cells was analyzed by RT-qPCR. "p $<0.05$. (B) T-47D cells were transfected with $50 \mathrm{pmol} / \mathrm{ml} \mathrm{NCO}$, miR-181b mimics or inhibitors. After $48 \mathrm{~h}$ of incubation, the cells were treated with DOX for another $48 \mathrm{~h}$. Cell viability was evaluated by MTT assay. The $\mathrm{IC}_{50}$ value was determined according to the survival curves. *p $<0.05$ vs. NCO group. (C) T-47D-R cells were transfected with $50 \mathrm{pmol} / \mathrm{ml}$ NCO, miR-181b mimics or inhibitors. After $48 \mathrm{~h}$ of incubation, the cells were treated with DOX for another $48 \mathrm{~h}$. Cell viability was evaluated by MTT assay. The $\mathrm{IC}_{50}$ value was determined according to the survival curves. "p $<0.05$ vs. $\mathrm{NCO}$ group. 
A
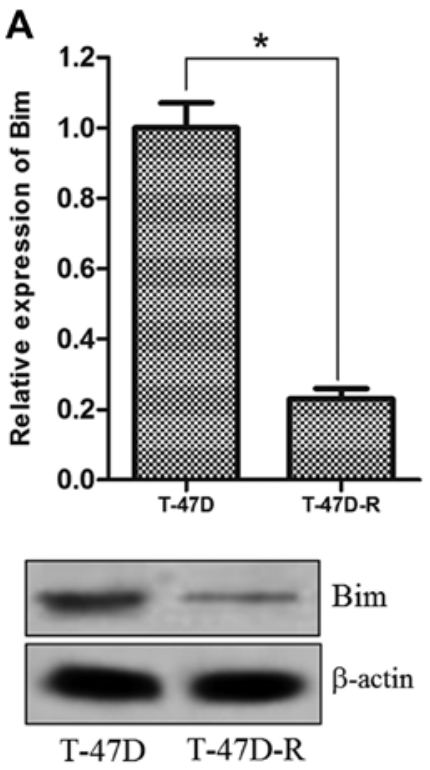

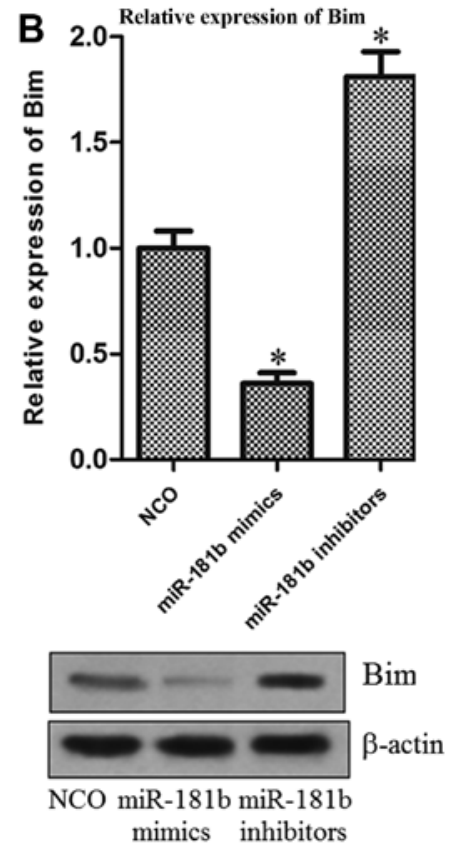

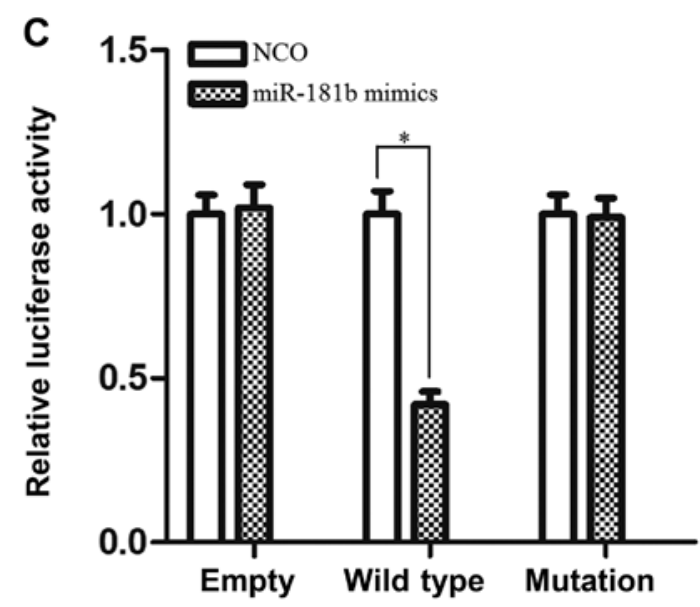

Figure 4. Bim is a target of miR-181b in T-47D-R cells. (A) The expression of Bim at the mRNA and protein levels in T-47D and T-47D-R cells was evaluated by RT-qPCR and western blot analysis. (B) T-47D-R cells were transfected with miR-181b mimics, miR-181b inhibitors or NCO (50 pmol/ml) followed by assay of mRNA and protein levels of Bim, respectively. " p<0.05 vs. NCO group. (C) Luciferase reporter assays in T-47D-R cells. Cells were transfected with wild-type or mutant Bim 3'-UTR-reporter constructs together with miR-181b mimics or NCO. Forty-eight hours post-transfection, the firefly luciferase activity was measured, and normalized to the Renilla luciferase using the Dual-Luciferase Reporter system.

the parental T-47D cells (Fig. 4A). Therefore, we inferred that the T-47D cells became DOX resistant by downregulating Bim expression, which is a target of miR-181b. To confirm this speculation, T-47D-R cells were transfected with miR-181b mimics, miR-181b inhibitors or NCO to alter the miR-181b level. As expected, a pronounced decrease in both Bim mRNA and protein levels was observed in the T-47D-R cells by transfection of the miR-181b mimics. On the contrary, the level of Bim was significantly upregulated when the miR-181b inhibitors were introduced into the T-47D-R cells (Fig. 4B). To further investigate whether Bim is directly targeted by miR-181b, a luciferase reporter vector was constructed, containing the putative miR-181b binding sites within the Bim 3'-UTR. The results showed that the relative luciferase activity of the reporter which contained wild-type 3'UTR of Bim was significantly inhibited in the miR-181b group compared with the control group. However, the mutations in the miR-181b binding site from the Bim 3'-UTR abolished this effect (Fig. 4C). Taken together, these results suggested that the expression of Bim was negatively regulated by miR-181b, which may play an essential role in the DOX resistance of breast cancer cells.

miR-181b inhibitors reverse DOX resistance through the miR-181b-Bim-MMP-caspase pathway. Our preceding results showed that miR-181b inhibitors reversed the DOX resistance in T-47D-R cells and that the Bim gene was the direct target of miR-181b. We, therefore, investigated the pathway and the relationship between Bim regulation and the antitumor effect of the treatment with DOX plus miR-181b inhibitors in T-47D-R cells. As Bim is the key member of the pro-apoptotic Bcl-2 family proteins (22), we found that the downregulation of miR-181b by its specific inhibitors significantly increased the apoptotic rate of the T-47D-R cells treated with DOX, and this synergistic effect of miR-181b inhibitors was abolished when Bim siRNA (after transfecion, the expression of Bim was reduced 
A

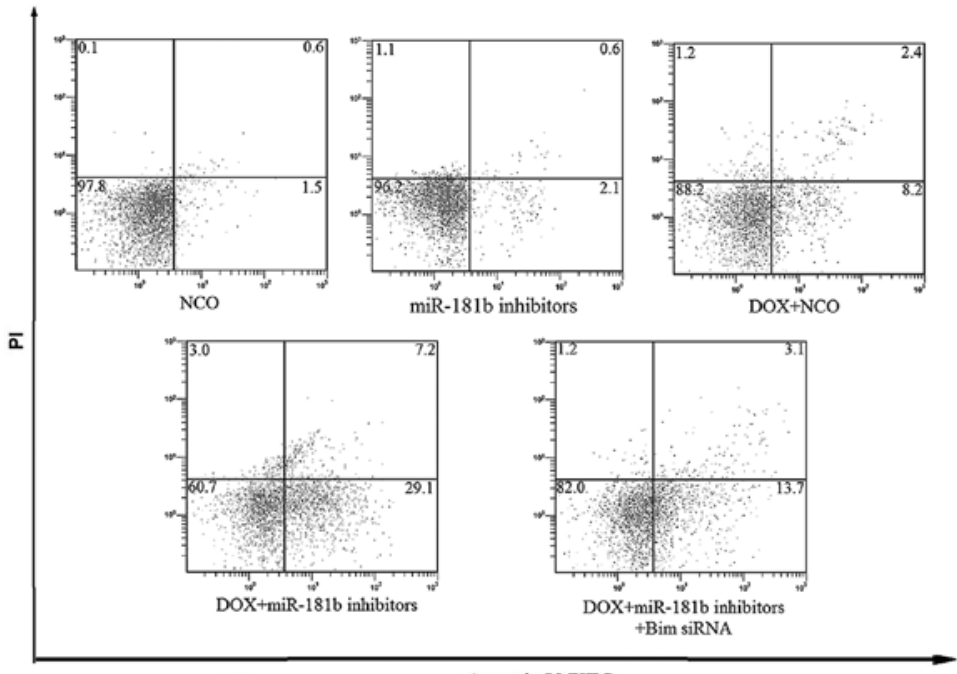

\section{B}
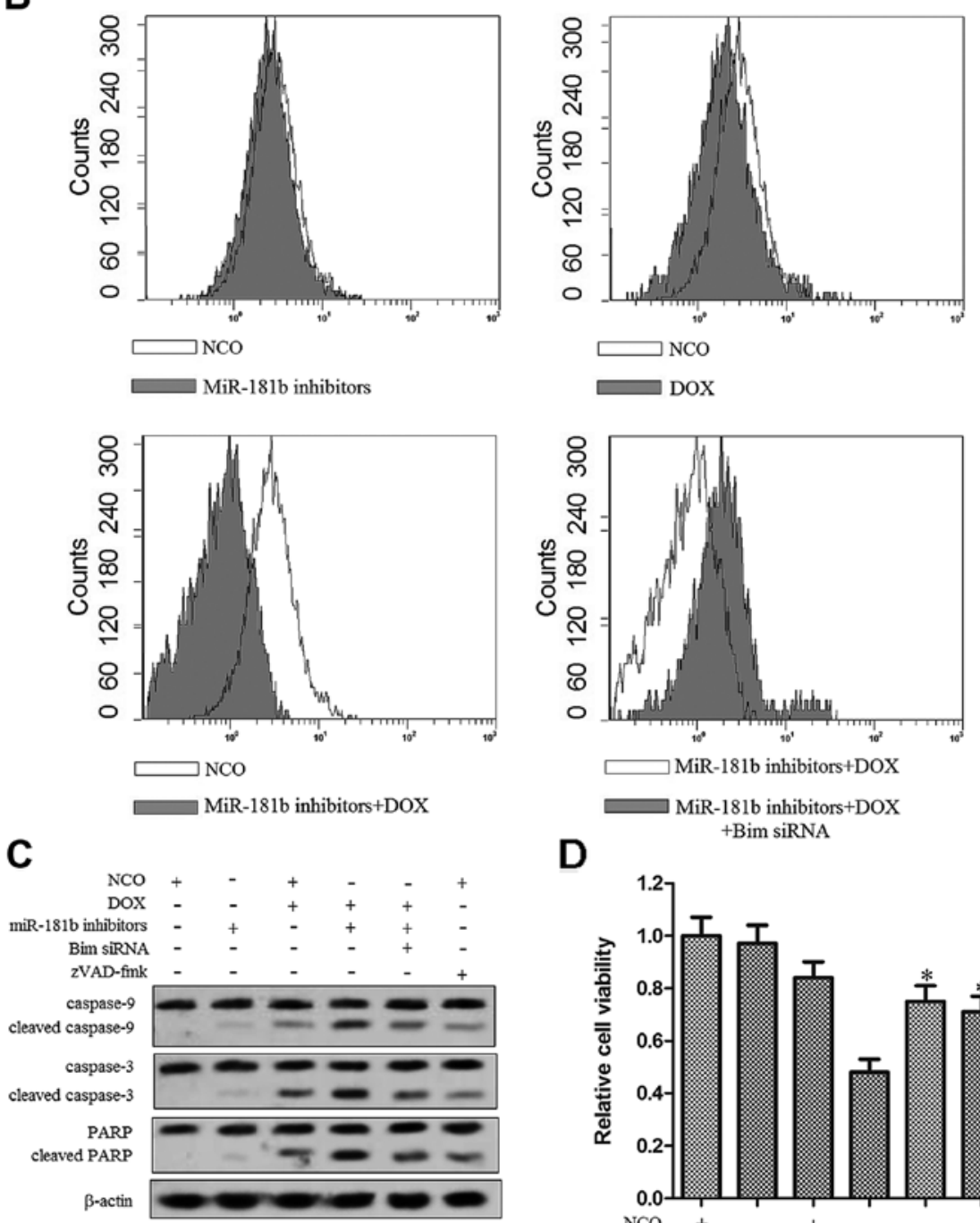

\section{D}

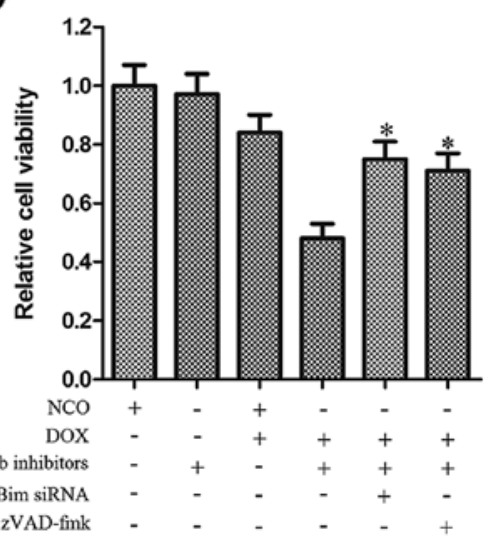

Figure 5. miR-181b inhibitors reverse DOX resistance through the miR-181b-Bim-MMP-caspase pathway. (A) T-47D-R cells were co-transfected with $50 \mathrm{pmol} / \mathrm{ml} \mathrm{Bim} \mathrm{siRNA} \mathrm{and/or} 50 \mathrm{pmol} / \mathrm{ml} \mathrm{miR}-181 \mathrm{~b}$ inhibitors for $48 \mathrm{~h}$. Then, the cells were treated with $5 \mu \mathrm{g} / \mathrm{ml}$ DOX for another $48 \mathrm{~h}$. The apoptotic rate was analyzed using flow cytometry. (B) T-47D-R cells were treated as described above, and the mitochondrial membrane potential was analyzed by JC-1

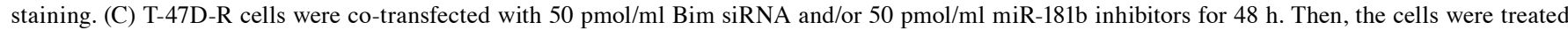
with $5 \mu \mathrm{g} / \mathrm{ml}$ DOX for another $48 \mathrm{~h}$ in the absence or presence of zVAD-fmk $(10 \mu \mathrm{M})$, and western blot analysis was performed to measure the activation of caspase- 9 and -3 and its substrate PARP. (D) T-47D-R cells were treated as described above, and cell viability was measured by MTT assay. "p<0.05 vs. DOX plus miR-181b inhibitor group. 
$\sim 5.12$-fold, data not shown) was co-transfected (Fig. 5A). The results indicated that $\mathrm{miR}-181 \mathrm{~b}$ regulated the DOX resistance via targeting the Bim gene. We next observed that although miR-181b inhibitors alone did not influence the MMP of the T-47D-R cells, they significantly promoted DOX to damage the mitochondria of the T-47D-R cells. Notably, the mitochondrial dysfunction caused by miR-181b inhibitors plus DOX was inhibited by Bim siRNA (Fig. 5B). Since a previous study indicated that intrinsic apoptosis is activated by mitochondrial dysfunction, mitochondrial-derived apoptogenic proteins are then released from mitochondria, leading to the activation of caspase- 9 which finally activates caspase-3 (23). Our results demonstrated that the apoptosis induced by miR-181b inhibitors plus DOX was caspase-dependent (Fig. 5C). Finally, using MTT assay, we indicated that both the Bim siRNA and zVAD-fmk significantly inhibited the cell death induced by DOX combined with the miR-181b inhibitors in the T-47D-R cells (Fig. 5D). Our data strongly suggest the important role of the Bim pathway in reversing the DOX resistance in breast cancer.

\section{Discussion}

Studies have demonstrated that miR-181b may act as an oncogene in multiple types of cancer. For instance, the upregulation of the miR-181 family promoted the growth, clonogenic survival, migration and invasion in hepatocellular carcinoma cells by targeting TIMP3 (24). It was also reported that expression levels of the miR-181 family were elevated in breast, colon and pancreatic cancer (25-27). Furthermore, miR-181b was found to contribute to the drug resistance of tamoxifen which is the irreplaceable drug for the treatment of breast cancer (28). Although the previous studies indicated that the miR-181b level is commonly upregulated in many types of tumor, the functions and targets concerning miR-181b remain unknown. In the present study, we showed that miR$181 \mathrm{~b}$ was significantly upregulated in the the blood of breast cancer patients and in breast cancer cell lines. Moreover, we also found that the expression level of miR-181b in breast cancer cells was positively related with cell proliferation and migration in vitro, suggesting that miR-181b acts as a tumor promoter in breast cancer.

Chemoresistance is the major limitation for achieving a satisfactory chemotherapeutic effect, and much effort has been made to prove that treatment using various miRNAs may improve the antitumor effect of chemotherapeutic drugs in multiple tumor types. For instance, the anti-miR-21 oligonucleotide significantly enhanced the chemosensitivity of glioblastoma cells to DOX by inducing apoptosis (29). Enforced expression of miR-26b improved the curative effect of hepatocellular carcinoma cells to TRAIL by downregulating the anti-apoptotic gene myeloid cell leukemia-1 (Mcl-1) (30). miR-193b was proven to act as a drug sensitizer, and promoted the induction of apoptosis following cisplatin treatment in hepatocellular carcinoma (31). In this context, it was of interest to examine whether or not miR-181b is associated with chemoresistance. We found that knockdown of miR-181b re-sensitized the T-47D-R cells to DOX, significantly decreasing the $\mathrm{IC}_{50}$ value of DOX. We further found the miR-181b mimics did not further impair the antitumor effect of DOX. We explained that the expression of miR-181b in the T-47D-R cells is high enough to have a biological effect so that the transfection of miR-181b mimics became unnecessary.

Bcl-2 interacting mediator of cell death [Bim, also known as B-cell chronic lymphocytic leukemia-lymphoma-like 11 (BCL2L11)], is a member of the Bcl-2 family genes and belongs to the $\mathrm{BH} 3$-only subfamily of Bcl-2 family proteins (32). Bim has emerged as a crucial regulator of the mitochondrial (intrinsic) apoptotic pathway, which directly activates the proapoptotic function, and binds to all of the pro-apoptotic Bcl-2 family members to promote cell apoptosis $(33,34)$. Recently, accumulating evidence shows that Bim deletion in cancers is associated with a poorer response to targeted therapy treatment $(35,36)$. Bim may act as a biomarker to predict the survival of cancer patients (37). According to our data, miR-181b inhibitors re-sensitized T-47D-R cells to DOX by targeting Bim, depending on the upregulation of the cellular level of Bim in chemoresistant cancer cells. To further explore the mechanisms, we tested the mitochondrial membrane potential which is downstream of the Bim pathway, which controls mitochondrial (intrinsic) apoptosis (38). We found that regain of Bim mediated by miR-181b inhibitors in T-47D-R cells significantly promoted DOX to damage the mitochondria, leading to a decrease in the mitochondrial membrane potential. As a result, caspase-9 which is a biomarker of intrinsic apoptosis was activated, following the cleavage of caspase-3 (39).

In conclusion, the present study provides evidence that miR-181b is a novel oncogene and one important factor for developing the chemoresistance in breast cancer. The results suggest that the miR-181b-Bim-MMP-caspase pathway may be a potential therapeutic target for the chemotherapy of breast cancer in the future.

\section{Acknowledgements}

The present study was supported by the Natural Science Foundation of Zhejiang Province (no. LY12H29004). The study was approved by the Ethics Committee of Zhejiang Cancer Hospital.

\section{References}

1. Siegel R, Naishadham D and Jemal A: Cancer statistics, 2013. CA Cancer J Clin 63: 11-30, 2013.

2. Weigelt B, Peterse JL and van 't Veer LJ: Breast cancer metastasis: Markers and models. Nat Rev Cancer 5: 591-602, 2005.

3. Jerusalem G, Rorive A and Collignon J: Chemotherapy options for patients suffering from heavily pretreated metastatic breast cancer. Future Oncol 11: 1775-1789, 2015.

4. Nakamura S, Yagata $H$, Ohno S, Yamaguchi $H$, Iwata $H$, Tsunoda N, Ito Y, Tokudome N, Toi M, Kuroi K, et al: Multicenter study evaluating circulating tumor cells as a surrogate for response to treatment and overall survival in metastatic breast cancer. Breast Cancer 17: 199-204, 2010.

5. Yao YS, Qiu WS, Yao RY, Zhang Q, Zhuang LK, Zhou F, Sun LB and Yue L: miR-141 confers docetaxel chemoresistance of breast cancer cells via regulation of EIF4E expression. Oncol Rep 33: 2504-2512, 2015

6. Xu F, Wang F, Yang T, Sheng Y, Zhong T and Chen Y: Differential drug resistance acquisition to doxorubicin and paclitaxel in breast cancer cells. Cancer Cell Int 14: 538, 2014.

7. Shuhendler AJ, Prasad P, Zhang RX, Amini MA, Sun M, Liu PP, Bristow RG, Rauth AM and Wu XY: Synergistic nanoparticulate drug combination overcomes multidrug resistance, increases efficacy, and reduces cardiotoxicity in a nonimmunocompromised breast tumor model. Mol Pharm 11: 2659-2674, 2014. 
8. Mohell N, Alfredsson J, Fransson Å, Uustalu M, Byström S, Gullbo J, Hallberg A, Bykov VJ, Björklund U and Wiman KG: APR-246 overcomes resistance to DOX and doxorubicin in ovarian cancer cells. Cell Death Dis 6: e1794, 2015.

9. Gao JH, Chen FH, Wang L, Wei H and Meng SL: YM155 inhibits tumor growth and enhances chemosensitivity to cisplatin in osteosarcoma. Eur Rev Med Pharmacol Sci 19: 2062-2069, 2015.

10. Ambros V: The functions of animal microRNAs. Nature 431: $350-355,2004$

11. Sevignani C, Calin GA, Siracusa LD and Croce CM: Mammalian microRNAs: A small world for fine-tuning gene expression. Mamm Genome 17: 189-202, 2006.

12. Ambros V: MicroRNA pathways in flies and worms: Growth, death, fat, stress, and timing. Cell 113: 673-676, 2003.

13. Calin GA, Sevignani C, Dumitru CD, Hyslop T, Noch E, Yendamuri S, Shimizu M, Rattan S, Bullrich F, Negrini M, et al: Human microRNA genes are frequently located at fragile sites and genomic regions involved in cancers. Proc Natl Acad Sci USA 101: 2999-3004, 2004.

14. Qiu F, Xiong JP, Deng J and Xiang XJ: TRIM29 functions as an oncogene in gastric cancer and is regulated by miR-185. Int J Clin Exp Pathol 8: 5053-5061, 2015.

15. Tian X, Xu L and Wang P: MiR-191 inhibits TNF- $\alpha$ induced apoptosis of ovarian endometriosis and endometrioid carcinoma cells by targeting DAPK1. Int J Clin Exp Pathol 8: 4933-4942, 2015.

16. Toraih EA, Mohammed EA, Farrag S, Ramsis N and Hosny S: Pilot study of serum nicroRNA-21 as a diagnostic and prognostic biomarker in Egyptian breast cancer patients. Mol Diagn Ther 19: 179-190, 2015

17. Kaboli PJ, Rahmat A, Ismail P and Ling KH: MicroRNA-based therapy and breast cancer: A comprehensive review of novel therapeutic strategies from diagnosis to treatment. Pharmacol Res 97: 104-121, 2015

18. Livak KJ and Schmittgen TD: Analysis of relative gene expression data using real-time quantitative PCR and the $2^{-\Delta \Delta C_{\mathrm{T}}}$ method. Methods 25: 402-408, 2001.

19. Czeczuga-Semeniuk E, Bielawski T, Lemancewicz D, Rusak M and Wołczyński S: Vitamin A family compounds, estradiol, and docetaxel in proliferation, apoptosis and immunocytochemical profile of human ovary endometrioid cancer cell line CRL-11731. Folia Histochem Cytobiol 47: S127-S135, 2009.

20. Prathapan A, Vineetha VP and Raghu KG: Protective effect of Boerhaavia diffusa L. against mitochondrial dysfunction in angiotensin II induced hypertrophy in $\mathrm{H} 9 \mathrm{c} 2$ cardiomyoblast cells. PLoS One 9: e96220, 2014.

21. Zahedifard M, Faraj FL, Paydar M, Yeng Looi C, Hajrezaei M, Hasanpourghadi M, Kamalidehghan B, Abdul Majid N, Mohd Ali H and Ameen Abdulla M: Synthesis, characterization and apoptotic activity of quinazolinone Schiff base derivatives toward MCF-7 cells via intrinsic and extrinsic apoptosis pathways. Sci Rep 5: 11544, 2015.

22. Frank DO, Dengjel J, Wilfling F, Kozjak-Pavlovic V, Häcker G and Weber A: The pro-apoptotic BH3-only protein Bim interacts with components of the translocase of the outer mitochondrial membrane (TOM). PLoS One 10: e0123341, 2015.

23. Geserick P, Wang J, Feoktistova $M$ and Leverkus $M$ : The ratio of Mcl-1 and Noxa determines ABT737 resistance in squamous cell carcinoma of the skin. Cell Death Dis 5: e1412, 2014.

24. Wang B, Hsu SH, Majumder S, Kutay H, Huang W, Jacob ST and Ghoshal K: TGFbeta-mediated upregulation of hepatic miR-181b promotes hepatocarcinogenesis by targeting TIMP3 Oncogene 29: 1787-1797, 2010.
25. Yan LX, Huang XF, Shao Q, Huang MY, Deng L, Wu QL, Zeng YX and Shao JY: MicroRNA miR-21 overexpression in human breast cancer is associated with advanced clinical stage, lymph node metastasis and patient poor prognosis. RNA 14: 2348-2360, 2008.

26. Nakajima G, Hayashi K, Xi Y, Kudo K, Uchida K, Takasaki K, Yamamoto M and Ju J: Non-coding MicroRNAs hsa-let-7g and $h s a-m i R-181 b$ are associated with chemoresponse to S-1 in colon cancer. Cancer Genomics Proteomics 3: 317-324, 2006.

27. Lee EJ, Gusev Y, Jiang J, Nuovo GJ, Lerner MR, Frankel WL, Morgan DL, Postier RG, Brackett DJ and Schmittgen TD: Expression profiling identifies microRNA signature in pancreatic cancer. Int J Cancer 120: 1046-1054, 2007.

28. Miller TE, Ghoshal K, Ramaswamy B, Roy S, Datta J, Shapiro CL, Jacob S and Majumder S: MicroRNA-221/222 confers tamoxifen resistance in breast cancer by targeting p $27^{\mathrm{Kip} 1}$. J Biol Chem 283 29897-29903, 2008.

29. Giunti L, da Ros M, Vinci S, Gelmini S, Iorio AL, Buccoliero AM, Cardellicchio S, Castiglione F, Genitori L, de Martino M, et al: Anti-miR21 oligonucleotide enhances chemosensitivity of T98G cell line to doxorubicin by inducing apoptosis. Am J Cancer Res 5: 231-242, 2015.

30. Jiang C, Long J, Liu B, Xie X and Kuang M: Mcl-1 Is a novel target of miR-26b that is associated with the apoptosis induced by TRAIL in HCC cells. Biomed Res Int 2015: 572738, 2015

31. Yin W, Nie Y, Zhang Z, Xie L and He X: miR-193b acts as a cisplatin sensitizer via the caspase-3-dependent pathway in HCC chemotherapy. Oncol Rep 34: 368-374, 2015.

32. Kivits RA and Furneaux C: BIM: Enabling sustainability and asset management through knowledge management. ScientificWorldJournal 2013: 983721, 2013.

33. Youle RJ and Strasser A: The BCL-2 protein family: Opposing activities that mediate cell death. Nat Rev Mol Cell Biol 9: 47-59, 2008.

34. O'Connor L, Strasser A, O'Reilly LA, Hausmann G, Adams JM, Cory S and Huang DC: Bim: A novel member of the Bcl-2 family that promotes apoptosis. EMBO J 17: 384-395, 1998.

35. Faber AC, Corcoran RB, Ebi H, Sequist LV, Waltman BA, Chung E, Incio J, Digumarthy SR, Pollack SF, Song Y, et al: BIM expression in treatment-naive cancers predicts responsiveness to kinase inhibitors. Cancer Discov 1: 352-365, 2011.

36. Shao YY, Chang YL, Huang CY, Hsu CH and Cheng AL: The germline BIM deletion polymorphism is not associated with the treatment efficacy of sorafenib in patients with advanced hepatocellular carcinoma. Oncology 85: 312-316, 2013.

37. Lee JH, Lin YL, Hsu WH, Chen HY, Chang YC, Yu CJ, Shih JY, Lin CC, Chen KY, Ho CC, et al: Bcl-2-like protein 11 deletion polymorphism predicts survival in advanced non-small-cell lung cancer. J Thorac Oncol 9: 1385-1392, 2014.

38. Weber K, Harper N, Schwabe J and Cohen GM: BIM-mediated membrane insertion of the BAK pore domain is an essential requirement for apoptosis. Cell Reports 5: 409-420, 2013.

39. Park C, Hong SH, Kim GY and Choi YH: So-Cheong-RyongTang induces apoptosis through activation of the intrinsic and extrinsic apoptosis pathways, and inhibition of the PI3K/Akt signaling pathway in non-small-cell lung cancer A549 cells. BMC Complement Altern Med 15: 113, 2015. 